\title{
STUDI KOMPARASI HARAPAN ORANG TUA SISWA SDSN DAN SD EKS RSBI DI DAERAH ISTIMEWA YOGYAKARTA
}

\section{A COMPARATIVE STUDY ON THE EXPECTATION OF THE PARENTS OF STUDENTS OF SDSN AND EX-RSBI SD IN YOGYAKARTA SPECIAL TERRITORY}

\author{
Aan Sofyan, Udik Budi Wibowo \\ Universitas Muhammadiyah Surakarta, Universitas Negeri Yogyakarta \\ sofyanspt@gmail.com, udik_bw@uny.ac.id
}

\begin{abstract}
Abstrak
Penelitian ini bertujuan untuk mengetahui perbedaan harapan orang tua siswa yang menyekolahkan anaknya di SDSN dan SD Eks RSBI. Penelitian ini menggunakan pendekatan kuantitatif dengan jenis penelitian komparasi. Populasi penelitian adalah orang tua siswa kelas I SDSN dan SD eks RSBI di Daerah Istimewa Yogyakarta (DIY). Sampel 322 orang tua siswa SDSN dan 226 orang tua siswa SD eks RSBI ditentukan dengan cluster random sampling technique. Instrumen penelitian yang digunakan berupa kuesioner harapan orang tua siswa. Instrumen penelitian dikembangkan berdasarkan enam kategori fungsi sekolah yaitu: (1) fungsi mengembangkan kecerdasan pikiran dan memberikan pengetahuan, (2) fungsi spesialisasi, (3) fungsi efisiensi, (4) fungsi sosialisasi, (5) fungsi konservasi, dan (6) fungsi transisi. Pengumpulan data menggunakan skala. Data dianalisis menggunakan statistik non-parametric, dengan menggunakan uji Mann-Whitney. Berdasarkan hasil penelitian yang diperoleh dapat disimpulkan bahwa tidak terdapat perbedaan antara harapan orang tua siswa SDSN dan SD eks RSBI di DIY. Hasil analisis uji Mann-Whitney menunjukkan nilai signifikansi 0,666 yang berarti bahwa hipotesis Ho diterima. Artinya, harapan orang tua siswa SDSN dan SD eks RSBI mengenai fungsi sekolah di DIY adalah sama. Secara keseluruhan baik orang tua siswa SDSN maupun orang tua siswa SD eks RSBI mengharapkan sekolah yang mereka pilih untuk anaknya bisa melaksanakan fungsinya dengan baik.
\end{abstract}

Kata Kunci: harapan, orang tua siswa, SDSN, SD eks RSBI.

\begin{abstract}
This study aimed to determine the differences in the expectations of parents who send their children to SDSN and SD Ex RSBI. This study uses the quantitative approach to the type of comparative research. The study population was parents of the students of elementary school class I SDSN and ex RSBI in Yogyakarta Special Territoy (YST). A sample of 322 SDSN students' parents and 226 Ex RSBI SD students' parents was established using the cluster random sampling technique. The research instrument used was in the form of a questionnaire on the expectations of the students' parents. The research instrument was developed based on six categories of school functions, namely:(1) function of developing intelligence of the mind and providing knowledge, (2) specialization function, (3) efficiency function, (4) socialization function, (5) conservation function, and (6) transition function. The data were collected using a questionaire with Likert scale and analyzed using the non-parametric statistics of Mann-Whitney test. Based on the results, it can be concluded that there is no difference between the expectations of parents of the students of SDSN and that of ex-RSBI in YST. The results of the Mann-Whitney test analysis showed a significance value of 0.666 which means that the hypothesis $\mathrm{HO}$ is accepted. This means that the expectations of the parents of SDSN students and that of the parents of Ex-RSBI SD students in terms functions in YST are the same. Overall both SDSN students' parents and ex-RSBI SD students' parents expect that the schools they choose for their children to carry out their functions properly.
\end{abstract}

Key words: expectation, parent, SDSN, SD eks RSBI. 


\section{Pendahuluan}

Pendidikan anak merupakan tanggung jawab bersama semua elemen masyarakat. $\mathrm{Mu}$ lai dari orang tua dalam keluarga, guru dalam sekolah dan pemerintah. Masing-masing elemen tersebut juga akan membentuk sebuah lingkungan pendidikan yang akan berpengaruh pada proses pembentukan individu baik secara langsung maupun tidak langsung. Menurut Jumali et al. (2008, p.48), orang tua dalam keluarga mempunyai tanggung jawab yang besar terhadap pendidikan anak. Hal ini menurut Jumali et al. (2008, p.48) dikarenakan orang tua dalam keluarga merupakan lingkungan pendidikan yang pertama dalam membentuk pola kepribadian anak.

Seiring dengan perkembangan zaman, kesadaran akan pendidikan dasar bagi anak oleh para orang tua meningkat. Menurut Suprianto (1998, p.78), persepsi masyarakat terhadap urgensi pendidikan dewasa ini sudah semakin mengarah pada fungsi investasi hidup. Gejala ini dapat dicermati pada pilihan pendidikan yang akan ditempuh dan pada mutu pendidikan yang dimasuki. Oleh karena itu masyarakat dalam menentukan pendidikan yang akan dipilih sudah bukan lagi mempertimbangkan jarak geografis maupun finansial tetapi lebih berdasarkan pada pertimbangan mutu serta prospek ke masa depan.

Harapan (expectancy) orang tua begitu tinggi dalam menyekolahkan anaknya pada sekolah unggulan. Dengan menyekolahkan anaknya pada sekolah yang berstandar nasional atau bertaraf internasional diharapkan anaknya memperoleh pendidikan yang lebih berkualitas. Sekolah unggulan di mata orang tua siswa, dapat memberikan pendidikan yang lebih unggul bila dibandingkan dengan sekolah-sekolah lain yang kualitasnya di bawah sekolah berstandar nasional atau internasional.

Sekolah sebagai tempat para siswa mengenyam pendidikan tentunya harus memiliki kualitas apabila ingin mewujudkan anak didik yang berkualitas pula. Sekolah-sekolah yang ada di Indonesia seharusnya memiliki standar mutu sesuai dengan aturan-aturan yang sudah ditetapkan, baik oleh pemerintah pusat, maupun pemerintah daerah. Standar ini diperlukan untuk dapat memenuhi harapan para peserta didik dan para orang tua murid yang mempercayakan anak didiknya pada lembaga sekolah yang telah dipilihnya. Menurut Griffith (2008, p.101), standar pada setiap tingkat pendidikan, harus mencerminkan, tidak hanya pengetahuan dan keterampilan yang harus diperoleh, tetapi juga nilai-nilai dan sikap yang penting pada dunia tempat siswa akan tinggal dan bekerja. Ini akan mencakup unsur-unsur seperti pembentukan karakter, patriotisme, perspektif layanan, toleransi, budaya non-kekerasan, dan menghormati hak asasi manusia, serta kehidupan manusia.

Pendirian Sekolah Standar Nasional (SSN) dan Rintisan Sekolah Bertaraf Internasional merupakan alternatif yang ditawarkan dalam rangka meningkatkan mutu pendidikan baik pada tingkat sekolah dasar, sampai pada tingkat atas. Hal ini sesuai dengan amanah Undang-undang No. 20 Tahun 2003 tentang Sistem Pendidikan Nasional. Penyelenggaraan dua tipe sekolah ini, didasari oleh tuntutan kebutuhan pembangunan bangsa di masa yang akan datang agar memiliki kemampuan dan kompetitif dengan bangsa-bangsa lain di dunia internasional. Untuk itu, anak didik harus dipersiapkan sedini mungkin melalui proses pendidikan di sekolah dasar hingga pendidikan tingkat atas dengan memperhatikan perbedaan potensi kecerdasan, kecakapan, bakat dan minat peserta didik, sehingga lulusan yang dihasilkan relevan dengan kebutuhan, baik kebutuhan individu, keluarga maupun kebutuhan masyarakat dan pembangunan bangsa di berbagai sektor, baik lokal, nasional, maupun internasional.

Akan tetapi, tidak semua kebijakan pemerintah berakhir pada pemberdayaan sekolah dan peningkatan mutu pendidikan di Indonesia. Terlebih karena ada kalanya suatu kebijakan ditetapkan bukan karena kebutuhan yang didasarkan atas analisis ilmiah dan objektif, tetapi ada faktor lain tanpa memikirkan efektivitas dan kualitas kebijakan itu sendiri (Maryono, 2010, p.4). Dalam Majalah Gatra edisi XIX Januari 2013, disebutkan bahwa salah satu sorotan krusial terhadap pelaksanaan RSBI yaitu melahirkan diskriminasi akses publik pada pendidikan bermutu. Pendididkan berkualitas menjadi barang mahal karena beban biaya tambahan yang diberikan terhadap orang tua siswa. Hal ini dapat memicu terjadinya komersialisasi sektor pendidikan dan belum mampu diakses oleh seluruh masyrakat.

Pelaksanaan kebijakan penetapan dan pendirian RSBI dan SBI pada implementasinya masih disertai timbulnya berbagai masalah. Beberapa kekurangan dan kendala yang menjadi persoalan telah ditemukan di beberapa sekolah SBI dan RSBI. Triwiyanto \& Sobri (2010, p.112) menyebutkan terdapat beberapa 
persoalan yang dirasakan oleh sekolah dalam upaya pemenuhan standar sarana dan prasarana. Keluhan yang sering didengar dari pemenuhan standar sarana dan prasarana adalah fasilitas praktik yang masih minimal dan belum mencapai standarisasi SBI, layanan informasi, dan data belum sepenuhnya berbasis IT.

Persoalan lain yang menjadi kontroversi terhadap pelaksanaan SBI dan RSBI adalah munculnya wacana yang mengatakan bahwa pelaksanaan SBI dan RSBI disebut inkonstitusional. Menurut pengamat pendidikan Triwiyanto \& Sobri (2010, p.117), SBI dan RSBI melanggar pasal 31 ayat (3) UUD 1945. Menurutnya pasal itu menegaskan bahwa "Pemerintah mengusahakan dan menyelenggarakan pendididkan nasional, bukan pendidikan internasional". Sekolah berlabel internasional berada di luar sistem pendidikan nasional yang diatur dalam pasal 31 ayat (3) UUD 1945.

Adanya ketimpangan kesempatan mengakses pendidikan bagi masyarakat mampu dengan masyarakat tidak mampu turut menambah persoalan dalam pelaksanaan SBI dan RSBI. Triwiyanto \& Sobri (2010, p.119) menjelaskan bahwa hal ini tentunya dapat menodai rasa keadilan bagi masyarakat Indonesia. Dalam UU sistem pendidikan disebutkan bahwa prinsip penyelenggaraan pendidikan harus demokratis dan berkeadilan serta tidak diskriminatif dengan menjunjung tinggi hak asasi manusia, keagamaan, nilai kultural, dan kemajemukan bangsa.

SBI dan RSBI pada pelaksanaanya juga ditemukan bahwa belum semua pendidik dan tenaga pendidikan memperoleh kesempatan yang sama dalam hal mengembangkan kompetensinya. Menurut Triwiyanto \& Sobri (2010, p.120), hal ini membawa implikasi bagi sekolah untuk melakukan pembinaan teknis profesi dan kompetensi pendidikan secara berkala serta memberikan dukungan kepada setiap pendidik dan tenaga kependidikan agar memperkaya kompetensi. Salah satu aspek penting dalam pendidikan pendidik dan tenaga kependidikan. Kondisi tenaga pendidik yang sampai saat sekarang masih terbiasa dengan sistem sentralistik dan masih memperlihatkan guru sebagai sosok kurang berdaya menyulitkan pelakasanaan kinerjanya dengan ideal. Selain itu, selamaini tenaga pendidik juga tidak dibiasakan untuk kreatif dan inovatif dalam pelaksanaan proses pendidikan.

Menurut KBBI (Alwi et al., 2007, p.388) harapan adalah: (1) sesuatu yang diharapkan, (2) keinginan supaya menjadi kenyataan, (3) orang yang diharapakan atau dipercaya. Jadi harapan orang tua siswa yakni keinginan orang tua siswa. Menurut Yamamoto (2010, p.191) harapan orangtua yaitu sebuah keyakinan yang realistis atau penilaian orang tua terhadap masa depan prestasi anak yang dapat dilihat dari prestasi dalam pendidikan serta tercapainya pendidikan yang berkualitas tinggi. Lebih lanjut menurut Yamamoto $(2010$, p.191) harapan orangtua didasarkan pada penilaian terhadap kemampuan akademik anak serta sumber daya yang tersedia untuk mendukung tingkat capaian prestasi anak

Menurut Chen (2001, p.140) harapan orang tua memiliki pengaruh besar terhadap kinerja akademik anak-anak. Chen (2001, p.140) menambahkan bahwa hal ini dapat terjadi pada semua latar belakang sosial, ekonomi, dan etnis. Sikap dan harapan orang tua terhadap pendidikan anak-anaknya sangat mempengaruhi perilaku dan prestasi siswa. Oleh karena itu, semua orang tua harus memberikan dorongan kepada anak-anak mereka untuk lebih tekun dalam belajar, memantau kebiasaan belajar anak-anak mereka, dan memelihara rasa ingin tahu, kreativitas, dan keyakinan mereka.

Menurut Doren (2012, p.10) dari berbagai penelitian yang telah dilakukan disimpulkan bahwa harapan orang tua terhadap kemampaun anaknya, pilihan pendidikan, dan pekerjaan di masa depan memiliki pengaruh yang kuat pada hasil yang dicapai anak-anaknya. Lebih lanjut Doren (2012, p.18) mengatakan harapan orang tua juga berhubungan dengan prestasi akademis anak mereka. Penelitian yang konsisten menunjukkan bahwa tingginya harapan yang dimiliki orang tua terhadap prestasi anak mereka, akan menghasilkan prestasi yang sepadan.

Beutel \& Anderson (2008, p.342) mengatakan bahwa keluarga dengan status sosio ekonomi (SES) yang tinggi memberikan sumber daya serta harapan yang tinggi untuk anakanaknya. Perbedaan sosio ekonomi dapat membuat orang tua berbeda dalam memandang soal pendidikan anak. Orang tua berpendapatan menengah sering menganggap pendidikan sebagai sesuatu yang seharusnya dilakukan oleh orang tua dan guru. Orang tua berpendapatan rendah lebih sering menganggap pendidikan adalah tugas guru saja (Santrock, 2010, p.95).

Menurut Vang (2006, p.28) pada umunya orang tua tidak pernah bertanya tentang bagaimana kurikulum atau teknik apa yang digunakan dalam mendidik anak di dalam kelas, tetapi orang tua cenderung lebih peduli terhadap nilai- 
nilai dan perilaku anak-anak yang di dapatkan dalam kelas. Lebih lanjut Beutel \& Anderson (2008, p.67) menjelaskan modal kehidupan sosial dalam keluarga dapat dinilai dari seberapa banyak komunikasi yang terjadi antara anak dan orang tua. Beutel \& Anderson (2008, p.350) menambahkan bahwa modal sosial dalam keluarga yang tercermin dari adanya interaksi orang tua mendorong timbulnya kesepakatan bersama antara orang tua dan anak-anaknya, khususnya harapan terhadap pendidikan.

Doren $(2012$, p.24) mengatakan bahwa orang tua yang memiliki harapan tinggi terhadap anaknya cenderung lebih percaya terhadap kemampuan dan potensi yang dimiliki anakanaknya. Oleh sebab itu, orang tua akan memberikan kesempatan, dukungan, dan dorongan kepada anak-anaknya dan bahkan ikut terlibat dalam usaha pencapaian prestasi belajar mereka. Sebaliknya, orang tua yang memiliki harapan rendah terhadap anaknya cenderung memiliki pandangan yang rendah terhadap kemampuan dan potensi yang dimiliki anak-anaknya.

Lebih lanjut Doren (2012, p.11) mengatakan bahwa hasil penelitian menunjukkan bahwa ekspektasi orang tua sewaktu-waktu bisa berubah-ubah, harapan orang tua bisa meninggi atau sebaliknya malah justru menurun. Dari masalah tersebut Doren (2012, p.11) menawarkan solusi untuk masalah tersebut, diantaranya yaitu: (1) lembaga personal maupun sekolah hendaknya membantu orang tua dalam menguraikan harapan orang tua terhadap putra dan putrinya berdasarkan pengalaman mereka sendiri, (2) sekolah dapat memberikan informasi dan mengkomunikasikan kepada orang tua mengenai dukungan, akomodasi, dan layanan yang tersedia untuk mendukung putra dan putri mereka dalam mencapai prestasi di sekolah, sehingga dapat memperkuat keyakinan dan harapan para orang tua, (3) sekolah juga harus bermitra dengan keluarga untuk mendukung dan terlibat dalam kegiatan tertentu yang berkaitan dengan usaha memaksimalkan kemampuan anak-anak.

Zhan (2006, p.963) berpendapat bahwa orang tua yang memiliki harapan yang tinggi kepada anak-anaknya akan menetapkan standar sekolah yang lebih tinggi untuk anak-anaknya. Lebih lanjut Zhan (2006, p.963) menjelaskan bahwa sekolah yang diharapkan oleh orang tua tersebut yaitu sekolah yang dapat mentransfer ilmu pengetahuan penting kepada anak-anaknya serta mengajarkan pentingnya nilai-nilai social dalam masyarakat. Harapan orang tua menurut
Zhan (2006, p.963) juga merupakan sebagai gambaran lingkungan dimana para orang tua dan ank-anaknya tinggal yang ikut berpengaruh terhadap pendidikan yang diterima oleh anakanaknya.

Menurut Raty et al. (2002, p.131) orang tua dengan pendidikan yang berbeda-beda akan memiliki harapan yang berbeda pula terhadap pendidikan anak-anaknya. Meski begitu, lebih lanjut Raty et al. (2002, p.131) menjelaskan bahwa posisi yang berbeda pada orang tua dalam hirarki pendidikan, akan menghasilkan pengalaman pendidikan yang berbeda. Hal ini lah yang menyebabkan perbedaan dalam menentukan pilihan sekolah untuk anak-anak.

Menurut Raty et al. (2002, p.141) perbedaan latar belakang pendidikan orang tua akan berpengaruh terhadap penilaian kompetensi anak. Raty et al. (2002, p.141) menjelaskan bahwa pada orang tua dengan latar pendidikan sekolah umum (academically educated) kompetensi anaknya di ukur dari seberapa baik tingkat kognisinya dan kemampuan menyelesaikan masalah. Raty et al. (2002, p.141) menambahkan bahwa Orangtua dengan latar pendidikan sekolah umum (academically educated) mempunyai harapan yang tinggi terhadap ketrampilan sosial yang dimiliki oleh anak-anaknya. Sedangkan menurut Raty et al. (2002, p.141) orang tua dengan latar pendidikan kejuruan (vocationally educated) lebih menekankan pada tingkat kreativitas anak-anak. Hal ini akan berpengaruh pada harapan orang tua terhadap pendidikan anaknya (Raty et al., 2002, p.141).

Menurut Raty et al. (2002, p.143) harapan orang tua terhadap pendidikan anak-anak bergantung pula pada jender. Raty et al. (2002, p.143) menjelaskan bahwa seorang ibu akan lebih berharap anak-anaknya dapat memiliki kemampuan akademis yang tinggi dari pada kemampuan praktis. Lebih lanjut Raty et el. (2002, p.145) juga menambahkan bahwa seorang ibu lebih memperhatikan perkembangan akademis anak-anak daripada seorang bapak.

Menurut Kim et al. (2012, p.13) harapan orang tua terhadap pendidikan anak-anak bergantung pada variasi ras, suku, mapun bangsa. Lebih lanjut Kim et al. (2012, p.13) menambahkan bahwa variasi ras maupun etnis tersebut berkaitan erat dengan status sosial ekonomi. Orang tua dengan banyak sumber daya yang dimiliki mempunyai harapan yang lebih tinggi terhadap pendidikan anak-anak (Kim et al. (2012, p.13). Lebih penting lagi Kim et al. (2012, p.13) menjelaskan bahwa tingkat ekono- 
mi orang tua sangat berpengaruh secara signifikan terhadap harapan orang tua pada pendidikan anak-anak. Kim et al. (2012, p.13) menjelaskan bahwa orang tua dengan penghasilan yang lebih tinggi akan memiliki harapan yang lebih tinggi pula terhadap kualitas pendidikan yang diperoleh anak-anaknya. Begitu juga sebaliknya menurut Kim et al. (2012, p.13) orang tua dengan penghasilan yang rendah akan mempunyai harapan yang lebih rendah terhadap pendidikan anak-anaknya.

Menurut Zhan (2006, p.972) orang tua dengan status ekonomi yang lebih tinggi akan membawa pengaruh positif pada harapan keterlibatan orang tua pada sekolah anak-anaknya. Lebih lanjut Zhan (2006, p.972) menjelaskan bahwa hubungan positif antara aset orang tua dengan harapan menunjukkan bahwa aset dapat mengubah cara pandang orang tua terhadap perkembangan dunia. Zhan (2006, p.972) menambahkan bahwa harapan seorang ibu terhadap pendidikan anak-anak akan berkaitan erat dengan capaian pendidikan anak-anaknya.

Li (2001, p.477) menjelaskan bahwa harapan orangtua secara signifikan dibentuk oleh pengalaman imigrasi dan akulturasi budaya. Li (2001, p.479) menambahkan bahwa keluarga yang berbeda dengan budaya yang berbeda pula maka harapan terhadap pendidikan anak-anak yang dimiliki para orang tua akan berbeda. Hal ini menurut Li (2001, p.477) karenakan oleh interpretasi yang berbeda terhadap harapan orang tua siswa pada pendidikan anak-anak.

Dari latar belakang tersebut dapat didentifikasi berbagai masalah antara lain yaitu harapan orang tua sangat tinggi dalam menyekolahkan anaknya pada sekolah unggulan baik SDSN maupun SD ks RSBI. Pemilihan masalah tersebut karena berdasarkan data yang ada antusias para orang tua yang begitu tinggi untuk menyekolahkan anaknya di sekolah yang menurut para orang tua memiliki kualitas unggul baik SDSN maupun SD eks RSBI.

Tujuan penelitian ini adalah mengetahui dan mengidentifikasi perbedaan harapan orang tua siswa yang menyekolahkan anaknya di SDSN dan orang tua siswa yang menyekolahkan anaknya di SD eks RSBI. Sedangkan manfaat penelitian ini yaitu Penelitian ini diharapkan memiliki manfaat antar lain: (1) hasil penelitian ini dapat dijadikan pertimbangan dalam merumuskan arah kebijakan di bidang pendidikan, terutama yang menyangkut penyelenggaraan pendidikan dasar; (2) dapat dijadikan sebagai bahan evaluasi bagi para kepala sekolah, apa- kah kinerja sekolah sudah berhasil memuaskan harapan masyarakat khususnya orang tua siswa; (3) dapat dijadikan pedoman bagi orang tua dalam memilih sekolah yang memberikan layanan pendidikan bagi anaknya.

\section{Metode}

Jenis Penelitian

Penelitian ini menggunakan metode kuantitatif dengan jenis penelitian komparatif. Penelitian yang dilakukan yaitu membandingkan antara harapan orang tua siswa SDSN dengan harapan orang tua siswa SD eks RSBI untuk mengetahui apakah ada perbedaan atau persamaan pada aspek tersebut.

Waktu dan Tempat Penelitian

Penelitian ini dilaksanakan di DIY. Waktu pelaksanaan penelitian dimulai pada Februari 2012 sampai dengan Mei 2013.

\section{Subjek Penelitian}

Populasi penelitian ini adalah semua orang tua siswa kelas satu SDSN dan SD eks RSBI yang ada di DIY. Pemilihan populasi orang tua siswa kelas satu lebih dikarenakan para orang tua siswa kelas satu dianggap mempunyai harapan yang masih tinggi terhadap sekolah yang dipilih untuk anak-anaknya. Menurut data dari Dikpora DIY jumlah keseluruhan siswa kelas I SDSN dan SD eks RSBI di DIY yaitu sebesar 2278. Jumlah siswa kelas I tersebut tersebar di 36 SDSN dan 5 SD eksRSBI di DIY. Teknik pengambilan sampel menggunakan teknik probability sampling dengan area (cluster) sampling. Sampel pada penelitian yaitu mengambil 5 kabupaten di DIY. Pengambilan sampel pada masing-masing Kabupaten berpedoman pada tabel Krejcie. Adapun jumlah sampel penelitian yaitu 322 orang tua siswa SDSN dan 296 orang tua siswa SD eks RSBI.

Prosedur

Teknik pengumpulan data yang digunakan dalam penelitian ini adalah dengan menggunakan kuesioner yang dibagikan kepada sumber data yaitu para orang tua siswa kelas 1 SDSN dan orang tua siswa kelas 1 SD eks RSBI. Instrumen penelitian yang digunakan adalah berupa kuesioner harapan orang tua siswa kelas 1 SDSN dan SD eks RSBI.

Instrumen penelitian dikembangkan berdasarkan 6 kategori fungsi sekolah seperti yang dijelaskan oleh Karsidi (2008, p.87). Enam 
fungsi sekolah tersebut yaitu: (1) fungsi mengembangkan kecerdasan pikiran dan memberikan pengetahuan, (2) fungsi spesialisasi, (3) fungsi efisiensi, (4) fungsi sosialisasi, (5) fungsi konservasi, (6) fungsi transisi. Instrumen penelitian yang diberikan kepada orang tua siswa diharapkan dapat mengukur tingkat harapan orang tua siswa terhadap 6 kategori fungsi sekolah tersebut. Instrumen penelitian disusun sedemikian rupa dengan menanyakan 34 item pertanyaan untuk mengukur seberapa tingkat "penting"nya dari masing-masing item pertanyaan yang ditulis dalam kuesioner. Agar tujuan pengisian isntrumen tercapai, instrumen penelitian disusun menggunakan model skala likert dengan pilihan jawaban: Sangat Penting (SP), Penting (P), Tidak Penting (TP), dan Sangat Tidak Penting (STP).

Teknik Analisis Data

Pengujian hipotesis penelitian ini, menggunakan teknik analisis komparasional bivariat. Teknik analisis komparasional bivariat adalah teknik analisis komparasional dengan variabel yang diperbandingkan hanya dua buah saja. Adapun dua variabel penelitan yang diteliti adalah harapan orang tua siswa SDSN dan harapan orang tua siswa SD eks RSBI.

Selanjutnya, dalam menganalisis adanya persamaan atau adanya perbedaan antara dua variabel penelitian ini. Data mengenai harapan orang tua siswa terhadap fungsi sekolah yang diperoleh dari orang tua siswa SDSN dan SD eks RSBI kemudian dianalisis dengan menggunakan program SPSS 16.0 for windows. Analisis data yang dilakukan yaitu dengan menguji normalitas data. Setelah dilakukan uji normalitas kemudian dilanjutkan dengan uji komparasi antar dua sampel independen. Setelah dilakukan uji normalitas data kemudian dianalisis menggunakan statistik non parametris.

Adapun uji statistik non parametris yang digunakan dalam analisis data orang tua siswa SDSN dan SD eks RSBI yaitu uji MannWhitney. Uji komparasi dilakukan untuk menguji Hipotesis nol (H0) yang mengatakan bahwa tidak ada perbedaan harapan orang tua siswa SDSN dan SD eks RSBI terhadap fungsi sekolah di DIY.

\section{Hasil dan Pembahasan}

Deskripsi Data Responden

Deskripsi data diri orang tua siswa yang diperoleh dari penyebaran kuesioner yaitu meli- puti umur, jenis kelamin, pendidikan, jenis pekerjaan dan jumlah anak. Adapun data mengenai umur orang tua SDSN dan SD eks RSBI per kabupaten di sajikan dalam Tabel 1.

Tabel 1. Rata-rata Umur Orang Tua Siswa

\begin{tabular}{|c|c|c|}
\hline \multirow{2}{*}{ Kabupaten/Kota } & \multicolumn{2}{|c|}{$\begin{array}{c}\text { Rerata Umur Orang Tua } \\
\text { (tahun) }\end{array}$} \\
\hline & SDSN & SD eks RSBI \\
\hline Yogyakarta & 37,43 & 40,02 \\
\hline Sleman & 37,50 & 39,87 \\
\hline Bantul & 36,55 & 37,64 \\
\hline Kulon Progo & 36,35 & 37,84 \\
\hline Gunungkidul & 38,64 & 38,24 \\
\hline Rata-rata & 37.43 & 38,73 \\
\hline
\end{tabular}

Dari Tabel 1 diketahui bahwa rata-rata umur orang tua siswa SD eks RSBI secara keseluruhan 38,73 tahun, sedangkan rata-rata umur orang tua siswa di SDSN secara keseluruhan 37,43 tahun. Berdasarkan hasil tersebut dapat diketahui bahwa umur orang tua siswa di SDSN lebih muda bila dibandingkan dengan rata-rata umur orang tua siswa di SD eks RSBI.

Tabel 2. Jenis Kelamin Orang Tua Siswa

\begin{tabular}{lcccc}
\hline \multirow{2}{*}{$\begin{array}{c}\text { Kabupaten/ } \\
\text { Kota }\end{array}$} & \multicolumn{3}{c}{ Jenis Kelamin Orang Tua } \\
& \multicolumn{3}{c}{ SDSN } & \multicolumn{3}{c}{ SD Eks RSBI } \\
\cline { 2 - 5 } & L & P & L & P \\
\hline Yogyakarta & 35 & 56 & 33 & 32 \\
Sleman & 32 & 24 & 28 & 27 \\
Bantul & 55 & 30 & 41 & 26 \\
Kulon Progo & 21 & 13 & 36 & 15 \\
Gunungkidul & 38 & 18 & 41 & 17 \\
\hline Total & 181 & 141 & 179 & 117 \\
\hline
\end{tabular}

L: Laki-laki, P: Perempuan

Dari Tabel 2. dapat diketahui jumlah orang tua siswa SDSN yang berjenis kelamin laki-laki 181 orang, sedangkan jumlah orang tua siswa yang berjenis kelamin perempuan 141 orang. Jumlah keseluruhan untuk orang tua siswa SD eks RSBI yang berjenis kelamin lakilaki 179 orang, sedangkan jumlah orang tua siswa yang berjenis kelamin perempuan 117 orang. 
Tabel 3. Tingkat Pendidikan Orang Tua Siswa SDSN

\begin{tabular}{lccccc}
\hline \multirow{2}{*}{ Kabupaten/Kota } & \multicolumn{5}{c}{ Tingkat Pendidikan } \\
& Orang Tua Siswa \\
\cline { 2 - 6 } & SD & SMP & SMA & S1 & S2 \\
\hline Yogyakarta & 1 & 2 & 42 & 44 & 2 \\
Sleman & 1 & 1 & 28 & 25 & 1 \\
Bantul & 13 & 12 & 48 & 12 & 0 \\
Kulon Progo & 0 & 1 & 21 & 12 & 0 \\
Gunungkidul & 15 & 10 & 24 & 6 & 1 \\
\hline Total & 30 & 26 & 163 & 99 & 4 \\
\hline
\end{tabular}

Dari Tabel 3. dapat diketahui bahwa secara berurutan jumlah orang tua siswa SDSN dengan latar belakang pendidikan SMA yaitu 163 , kemudian diikuti dengan jenjang pendidikan, S1, SD, SMP, dan S2 masing-masing sebesar 99, 30, 26, dan 4 responden. Dari data tersebut dapat diketahui pula bahwa mayoritas orang tua siswa SDSN berpendidikan SMA.

Tabel 4. Tingkat Pendidikan Orang Tua Siswa SD Eks RSBI

\begin{tabular}{lccccc}
\hline \multirow{2}{*}{ Kabupaten/Kota } & \multicolumn{5}{c}{ Tingkat Pendidikan } \\
\cline { 2 - 6 } & SD & SMP & SMA & S1 & S2 \\
\hline Yogyakarta & 0 & 4 & 36 & 24 & 1 \\
Sleman & 2 & 0 & 28 & 24 & 1 \\
Bantul & 0 & 4 & 31 & 27 & 5 \\
Kulon Progo & 0 & 1 & 17 & 29 & 4 \\
Gunungkidul & 0 & 2 & 31 & 23 & 2 \\
\hline Total & 2 & 11 & 143 & 127 & 13 \\
\hline
\end{tabular}

Dari Tabel 4. dapat diketahui bahwa secara berurutan jumlah orang tua siswa SD eks RSBI dengan latar belakang pendidikan SMA yaitu 143, kemudian diikuti dengan jenjang pendidikan, S1, S2, SMP, dan SD masingmasing sebesar 127, 13, 11, dan 2 responden. Dari data tersebut dapat diketahui pula bahwa mayoritas orang tua siswa SD eks RSBI berpendidikan SMA.

Tabel 5. Jenis Pekerjaan Orang Tua Siswa SDSN

\begin{tabular}{lcccc}
\hline \multirow{2}{*}{$\begin{array}{c}\text { Kabupaten/ } \\
\text { Kota }\end{array}$} & \multicolumn{4}{c}{ Jenis Pekerjaan Orang Tua Siswa } \\
\cline { 2 - 5 } & PNS & $\begin{array}{c}\text { TNI/ } \\
\text { POLRI }\end{array}$ & Swasta & $\begin{array}{c}\text { Buruh/ } \\
\text { Tani }\end{array}$ \\
\hline Yogyakarta & 7 & 0 & 31 & 53 \\
Sleman & 11 & 1 & 31 & 13 \\
Bantul & 6 & 0 & 32 & 47 \\
Kulon Progo & 7 & 2 & 14 & 11 \\
Gunungkidul & 6 & 0 & 23 & 27 \\
\hline Total & 37 & 3 & 131 & 151 \\
\hline
\end{tabular}

Dari Tabel 5 diketahui bahwa orang tua siswa SDSN mayoritas menyandang pekerjaan sebagai buruh/tani yaitu berjumlah 151 responden, kemudian disusul wiraswasta, PNS dan TNI/POLRI masing-masing berjumlah 131, 37 dan 3 responden.

Tabel 6. Jenis Pekerjaan Orang Tua Siswa SD Eks RSBI

\begin{tabular}{lcccc}
\hline \multirow{2}{*}{$\begin{array}{c}\text { Kabupaten/ } \\
\text { Kota }\end{array}$} & \multicolumn{4}{c}{ Jenis Pekerjaan Responden } \\
\cline { 2 - 5 } & PNS & $\begin{array}{c}\text { TNI/ } \\
\text { POLRI }\end{array}$ & Wiraswasta & $\begin{array}{c}\text { Buruh/ } \\
\text { Tani }\end{array}$ \\
\hline Yogyakarta & 10 & 1 & 21 & 33 \\
Sleman & 5 & 2 & 29 & 19 \\
Bantul & 18 & 3 & 23 & 23 \\
Kulon Progo & 16 & 6 & 19 & 10 \\
Gunungkidul & 14 & 3 & 28 & 13 \\
\hline Total & 63 & 15 & 120 & 98 \\
\hline
\end{tabular}

Dari Tabel 6 diketahui bahwa orang tua siswa SD eks RSBI mayoritas menyandang pekerjaan sebagai wiraswasta yaitu berjumlah 120 responden, kemudian disusul buruh/tani, PNS dan TNI/POLRI masing-masing berjumlah 98, 63 dan 15 responden.

Analisis Data Kuesioner Harapan Orang Tua Siswa

Hasil uji normalitas harapan orang tua siswa SDSN dan SD eks RSBI terhadap fungsi sekolah untuk DIY disajikan dalam Tabel 7.

Tabel 7. Uji Normalitas Data Harapan Orang

Tua Siswa SDSN dan SD eks RSBI DIY

\begin{tabular}{lcccccc}
\hline \multirow{2}{*}{ Grup_sekolah } & \multicolumn{2}{c}{$\begin{array}{c}\text { Kolmogorov- } \\
\text { Smirnov }\end{array}$} & \multicolumn{3}{c}{ Shapiro-Wilk } \\
\cline { 2 - 7 } & $\begin{array}{l}\text { Statistic } \\
\text { RSBI }\end{array}$ & df & Sig. & Statistic & df & Sig. \\
\hline SDSN & .131 & 296 & .000 & .912 & 296 & .000 \\
\hline
\end{tabular}

Hasil analisis uji normalitas data harapan orang tua siswa SDSN seperti yang disajikan pada Tabel 7. menunjukkan bahwa hasil uji Kolmogorov-Smirnov dengan nilai signifikansi sebesar 0,000. Hal ini menunjukkan bahwa data harapan orang tua siswa SDSN tidak berdistribusi normal karena nilai signifikansi hasil uji Kolmogorov-Smirnov kurang dari 0,05. Selain itu, uji normalitas data yang menggunakan uji Shapiro-Wilk dengan signifikansi yang sama yaitu 0,000 menunjukkan data responden tidak berdistribusi normal karena nilai signifikansinya kurang dari 0,05 . 
Hasil analisis uji normalitas data harapan orang tua siswa SD eks RSBI dengan uji Kolmogorov-Smirnov seperti yang tertera pada Tabel 7. menunjukkan nilai signifikansi 0,000. Hal ini berarti bahwa data harapan orang tua siswa SD eks RSBI tidak berdistribusi normal karena nilai signifikansi uji KolmogorovSmirnov kurang dari 0,05 . Selain itu, uji normalitas data yang menggunakan uji ShapiroWilk dengan signifikansi yang sama yaitu 0,000 menunjukkan data responden tidak berdistribusi normal karena nilai signifikansinya kurang dari 0,05 .

Adapun uji statistik nonparametris yang digunakan dalam analisis data orang tua siswa SDSN dan SD eks RSBI yaitu uji MannWhitney. Tabel 8. menyajikan data uji MannWhitney orang tua siswa SDSN dan eks RSBI DIY.

Tabel 8. Hasil Uji Mann-Whitney Harapan Orang Tua Siswa SDSN dan SD eks RSBI di DIY

\begin{tabular}{lr}
\hline & Skor_harapan \\
\hline Mann-Whitney U & 46703.000 \\
Wilcoxon W & 98706.000 \\
Z & -.431 \\
Asymp. Sig. (2-tailed) & .666 \\
\hline
\end{tabular}

Hasil analisis uji Mann-Whitney pada Tabel 8. menunjukkan bahwa nilai signifikansi dari uji tersebut yaitu 0,666 dengan nilai alfa $(\alpha)=0,05$. Apabila nilai signfikansi lebih besar dari 0,05 maka hipotesis $\mathrm{H}_{0}$ diterima. Pada Tabel 8. hasil pengolahan dengan SPSS 17.0 for windows didapat nilai signifikansi yang lebih besar dari $0,05(0,666 \geq 0,05)$, maka dapat disimpulkan bahwa $\mathrm{H}_{0}$ diterima. Hal ini berarti bahwa hipotesis penelitian yang mengatakan bahwa tidak ada perbedaan antara harapan orang tua siswa SDSN dan SD eks RSBI diterima. Artinya bahwa harapan orang tua siswa SDSN dan SD eks RSBI terhadap enam kategori fungsi sekolah di DIY adalah sama.

Pembahasan

Berdasarkan hasil uji perbandingan antara harapan orang tua siswa SDSN dan SD eks RSBI di DIY terbukti bahwa tidak terdapat perbedaan antara harapan orang tua siswa SDSN dan SD eks RSBI. Orang tua siswa SDSN dan SD eks RSBI sama-sama mempunyai harapan terhadap enam fungsi sekolah yang di uraikan dalam kuesioner penelitian. Enam fungsi sekolah menurut Karsidi (2008, p.48) tersebut yaitu: fungsi mengembangkan kecerdasan pikiran dan memberikan pengetahuan, fungsi spesialisasi, fungsi efisiensi, fungsi sosialisasi, fungsi konversi dan transmisi kultural, serta fungsi transmisi dari rumah ke masyarakat.

Secara keseluruhan baik orang tua siswa SDSN maupun orang tua siswa SD eks RSBI mengharapkan sekolah yang mereka pilih untuk anaknya bisa melaksanakan fungsinya dengan baik. Mereka berharap mendapatkan yang terbaik dari sekolah yang dipilih untuk anak-anaknya. Hal ini ditunjukkan dari jumlah skor data hasil perhitungan masing-masing orang tua siswa baik orang tua siswa SDSN maupun orang tua siswa SD eks RSBI. Jumlah skor keseluruhan hasil perhitungan poin yang dipilih oleh orang tua siswa SDSN adalah 40175. Apabila jumlah tersebut dirata-rata terhadap jumlah sampel keseluruhan responden orang tua siswa SDSN maka didapat jumlah nilai rata-rata per responden sebesar 124,76. Lebih lanjut apabila jumlah nilai rata-rata per responden dibagi dengan jumlah total item pertanyaan yang terdapat dalam kuesioner maka akan diketahui nilai ratarata per item pertanyaan dalam kuesioner sebesar 3,66. Demikian juga dengan responden orang tua siswa SD eks RSBI, jumlah skor keseluruhan hasil perhitungan poin yang dipilih oleh responden orang tua siswa SD eks RSBI adalah 36939. Apabila jumlah tersebut diratarata berdasarkan jumlah sampel keseluruhan reponden orang tua siswa SD eks RSBI maka didapat jumlah nilai rata-rata per responden sebesar 124,79. Lebih lanjut apabila jumlah nilai rata-rata per responden dibagi dengan jumlah total item pertanyaan yang terdapat dalam kuesioner maka akan dapat diketahui nilai ratarata per item pertanyaan dalam kuesioner sebesar 3,67. Hal ini berarti bahwa setiap responden orang tua siswa SDSN dan SD eks RSBI di D.I. Yogyakarta menganggap "sangat penting" dan "penting" sekolah yang dipilih untuknya dapat menjalankan enam fungsi sekolah tersebut.

Hasil penelitian yang menunjukkan tidak adanya perbedaan antara harapan orang tua siswa SDSN dan SD eks RSBI dapat dikarenakan oleh beberapa faktor. Faktor yang pertama yaitu bahwa responden penelitian dalam hal ini orang tua siswa SDSN maupun SD eks RSBI mempunyai tingkatan usia yang relatif sama. Ratarata umur orang tua siswa SDSN yaitu 37.43 tahun, sedangkan rata-rata umur orang tua siswa SD eks RSBI yaitu 38.73 tahun. Persamaan umur inilah yang membuat cara pandang (mindset) orang tua siswa bisa sama dalam menen- 
tukan harapan terhadap pendidikan pendidikan anak-anaknya. Menurut Li (2001, p.477) harapan orangtua secara signifikan dibentuk oleh pengalaman imigrasi dan akulturasi budaya. Perbedaan budaya menurut Li (2001, p.479) dapat menyebabkan perbedaan perspektif dalam menentukan harapan pendidikan anak. Menurut Li (2001, p.479) keluarga yang berbeda dengan budaya yang berbeda maka berbeda pula harapan terhadap pendidikan anak-anak yang dimiliki para orang tua akan berbeda. Hal ini menurut $\mathrm{Li}$ (2001, p.477) karenakan oleh interpretasi yang berbeda terhadap harapan orang tua siswa pada pendidikan anak-anak. Lebih lanjut dijelaskan oleh Yamamoto (2010, p.191) bahwa harapan orangtua yaitu sebuah keyakinan yang realistis atau penilaian orang tua terhadap masa depan prestasi anak yang dapat dilihat dari prestasi dalam pendidikan serta tercapainya pendidikan yang berkualitas tinggi.

Faktor yang menyebabkan hasil penelitian menunjukkan tidak adanya perbedaan harapan orang tua siswa SDSN dengan SD eks RSBI yang berikutnya yaitu jenis kelamin responden atau orang tua siswa SDSN dan SD eks RSBI. Hasil analisis deskripsi terhadap jenis kelamin responden SDSN maupun SD eks RSBI di DIY menunjukkan rata-rata jumlah responden berasal dari jenis kelamin laki-laki. Jumlah responden dari SDSN yang berjenis kelamin laki-laki sebesar $56,2 \%$ dan yang berjenis kelamin perempuan $43,8 \%$ dari jumlah total responden yang berasal dari SDSN. Sedangkan jumlah responden dari SD eks RSBI yang berjenis kelamin laki-laki sebesar $60 \%$ dan yang berejnis kelamin perempuan $40 \%$ dari jumlah total respondenyang berasal dari SD eks RSBI. Dari hasil tersebut dapat dinyatakan bahwa baik responden dari SDSN maupun SD eks RSBI mayoritas sama-sama berjenis kelamin lakilaki. Menurut Raty et al. (2002, p.143) harapan orang tua terhadap pendidikan anak-anak bergantung pula pada jender. Lebih lanjut Raty et al. (2002, p.143) menjelaskan bahwa seorang ibu (perempuan) akan lebih berharap anakanaknya dapat memiliki kemampuan akademis yang tinggi dari pada kemampuan praktis. Raty et el. (2002, p.143) menambahkan bahwa seorang ibu lebih memperhatikan perkembangan akademis anak-anak daripada seorang bapak.

Menurut Kim et al. (2012, p.13) harapan orang tua terhadap pendidikan anak-anak bergantung pada variasi ras, suku, mapun bangsa. Lebih lanjut Kim et al. (2012, p.13) menambahkan bahwa variasi ras maupun etnis tersebut berkaitan erat dengan status sosial ekonomi. Hal ini sesuai dengan kondisi orang tua siswa baik SDSN maupun SD eks RSBI. Responden dalam penelitian yang dilakukan di DIY baik SDSN maupun SD eks RSBI adalah sama-sama mayoritas berasal dari suku yang sama yaitu jawa. Faktor inipula yang dapat menyebabkan kesamaan dalam menentukan harapan pendidikan untuk anak-anaknya.

Faktor lain yang dapat menyebabkan hasil penelitian tidak ditemukan perbedaan harapan orang tua siswa SDSN maupun SD eks RSBI yaitu adanya kesamaan status pekerjaan orang tua siswa SDSN maupun SD eks RSBI. Analisis deskripsi responden penelitian menunjukkan bahwa baik orang tua SDSN maupun orang tua siswa SD eks RSBI mayoritas berstatus pekerjaan wiraswasta. Hal inilah yang dapat menyebabkan kesamaan harapan orang tua siswa SDSN dan SD eks RSBI. Status pekerjaan orang tua siswa akan berimplikasi terhadap status sosio ekonomi. Menurut Beutel \& Anderson (2008, p.342) keluarga dengan status sosio ekonomi (SES) yang tinggi memberikan sumber daya serta harapan yang tinggi untuk anak-anaknya. Beutel \& Anderson (2008, p.342) menambahkan bahwa perbedaan sosio ekonomi dapat membuat orang tua berbeda dalam memandang soal pendidikan anak. Lebih lanjut Beutel \& Anderson (2008, p.342) menjelaskan bahwa orang tua berpendapatan menengah sering menganggap pendidikan sebagai sesuatu yang seharusnya dilakukan oleh orang tua dan guru. Sedangkan menurut Santrock (Santrock, 2010, p.95) orang tua berpendapatan rendah lebih sering menganggap pendidikan adalah tugas guru saja. Doren $(2012$, p.37) menambahkan bahwa menurut teori kognitif sosial kesepahaman antara harapan orang tua dengan harapan anak-anak dalam hal pendidikan dapat terjadi jika harapan mereka saling terkait. Hal ini dapat terjadi pula ketika masing-masing individu baik anak, maupun orang tua, saling mengungkapkan harapan pendidikan mereka.

Hal yang sama juga dijelaskan oleh Kim et al. (2012, p.13) Orang tua dengan banyak sumber daya yang dimiliki mempunyai harapan yang lebih tinggi terhadap pendidikan anakanak. Lebih penting lagi Kim et al. (2012, p.13) menjelaskan bahwa tingkat ekonomi orang tua sangat berpengaruh secara signifikan terhadap harapan orang tua pada pendidikan anak-anak. Kim et al. (2012, p.13) menjelaskan bahwa orang tua dengan penghasilan yang lebih tinggi akan memiliki harapan yang lebih tinggi pula 
terhadap kualitas pendidikan yang diperoleh anak-anaknya. Begitu juga sebaliknya menurut Kim et al. (2012, p.13) orang tua dengan penghasilan yang rendah akan mempunyai harapan yang lebih rendah terhadap pendidikan anakanaknya. Zhan (2006, p.972) menambahkan bahwa orang tua dengan status ekonomi yang lebih tinggi akan membawa pengaruh positif pada harapan keterlibatan orang tua pada sekolah anak-anaknya.

Faktor berikutnya lagi yang dapat menyebabkan tidak ditemukannya perbedaan antara harapan orang tua siswa SDSN maupun SD eks RSBi yaitu adanya kesamaan status pendidikan yang dimiliki oleh para responden. Hasil analisis deskripsi terhadap data responden penelitian menunjukkan bahwa mayoritas pendidikan yang dimiliki oleh orang tua siswa baik SDSN maupun SD eks RSBI yaitu berpendidikan Sekolah Menengah Umum Atas (SMA). Dari hasil analisis deskripsi menunjukkan bahwa 50,6\% orang tua siswa SDSN berlatar belakang pendidikan SMA, sedangkan sisanya berlatar belakang pendidikan SD, SMP dan Sarjana. Begitu juga dengan orang tua SD eks RSBI $48 \%$ berpendidikan SMA, sedangkan sisanya berlatar pendidikan SD, SMP, dan Sarjana. Kesamaan dalam hal mayoritas status pendidikan orang tua inilah yang dapat menyebabkan persamaan harapan orang tua terhadap pendidikan anakanak. Menurut Raty et al. (2002, p.131) orang tua dengan pendidikan yang berbeda-beda akan memiliki harapan yang berbeda pula terhadap pendidikan anak-anaknya. Meski begitu, lebih lanjut Raty et al. (2002, p.131) menjelaskan bahwa posisi yang berbeda pada orang tua dalam hirarki pendidikan, akan menghasilkan pengalaman pendidikan yang berbeda. Hal ini lah menurut Raty et al. (2002, p.131) yang menyebabkan perbedaan dalam menentukan pilihan sekolah untuk anak-anak.

\section{Simpulan dan Saran}

Simpulan

Berdasarkan hasil penelitian yang diperoleh dapat disimpulkan bahwa tidak terdapat perbedaan antara harapan orang tua siswa SDSN dan SD eks RSBI di DIY. Hasil analisis uji Mann-Whitney menunjukkan nilai signifikansi 0,666 yang berarti bahwa hipotesis $\mathrm{H}_{0}$ diterima. Artinya, harapan orang tua siswa SDSN dan SD eks RSBI mengenai fungsi sekolah di DIY adalah sama. Secara keseluruhan baik orang tua siswa SDSN maupun orang tua siswa SD eks
RSBI mengharapkan sekolah yang mereka pilih untuk anaknya bisa melaksanakan fungsinya dengan baik.

Saran

Berdasarkan simpulan hasil penelitian, saran yang bisa peneliti sampaikan antara lain yaitu: (1) Sekolah eks RSBI dan SSN yang dianggap oleh banyak masyarakat sebagai sekolah unggulan hendaknya harus lebih meningkatkan mutu pendidikan agar masyarakat lebih percaya dalam mewujudkan harapan pendidikan anaknya, (2) Pemerintah sebagai pembuat kebijakan seharusnya menyediakan sekolah-sekolah unggulan yang dapat dinikmati oleh masyarakat luas, bukan hanya sebagian kecil masyarakat saja, (3) Perlu diadakan penelitian lanjutan mengenai harapan orang tua siswa secara kualitatif.

\section{Daftar Pustaka}

Alwi, et al. (2007). Kamus besar Bahasa Indonesia. Edisi ketiga. Jakarta: Balai Pustaka.

Beutel, A. M. \& Anderson, K. G. (2008). Race and the educational expectations of parents and children: The case of South Africa. The Sociological Quarterly, 56, pp.335-361.

Chen, H. (2001). Parents' attitudes and expectations regarding science education: Comparisons among American, Chinese-American, and Chinese families. Adolescence Journal, 36.142

Doren, B., Gau, J. M., \& Lindstrom, L. E. (2012). The relationship between parent expectations and postschool outcomes of adolescents with disabilities. Exceptional Children 79.1, pp.7-23.

Griffith, S.A. (2008). A proposed model for assessing quality of education. International Review of Education 54, pp.99-112.

Jumali et al. (2008). Landasan pendidikan cetakan 3. Surakarta: Muhammadiyah University Pers.

Karsidi, R. (2008). Sosiologi pendidikan cetakan 2. Surakarta: LPP UNS dan UNS Pers.

Kim, Y., Sherraden, M., \& Clancy, M. (2012). Parental educational expectations by racelethnicity and socioeconomic 
status. Education Research Symposium, University of Kansas.

Li, J. (2001). Expectations of Chinese Immigrant Parents for Their Children's Education: The Interplay of Chinese Tradition and the Canadian Context. Canadian Journal Of Education 26, 4 (2001): pp.477-494.

Maryono. (2010). Menakar kebijakan RSBI: analsis kritis studi implementasi. Yogyakarta: Magnum Pustaka.

Raty H., Leinonen T. \& Snellman, L. (2002). Parents' educational expectations and their social-psychological patterning. Scandinavian Journal of Educational Research, Vol. 46, No. 2. pp.129-144.

Santrock, J. W. (2010). Psikologi pendidikan. Jakarta: PT Fajar Interpratama Offset.

Suprianto, E. (1998). Manajemen dan akses pendidikan dasar terhadap demokrati- sasi pendidikan. Jurnal Varidika,16, pp.113-121.

Triwiyanto, T. \& Sobri, A.Y. (2010). Panduan mengelola sekolah bertaraf internasional. Yogakarta: Ar-Ruz Media.

Vang, C. T. (2006). Minority parents should know more about school culture and its impact on their children's education. Multicultural Education 14.1, pp.20-26.

Yamamoto, Y., \& Holloway, S. D. (2010). Parental expectations and children's academic performance in sociocultural context. Educ Psychol Rev (2010) 22, pp.189-214.

Zhan, M. (2006). Assets, parental expectations and involvement, and children's educational performance. Children and Youth Services Review. 28 (2006) pp.961-975. 